\title{
Arm function after stroke: measurement and recovery over the first three months
}

\author{
ANDREW HELLER, DERICK T WADE, VICTORINE A WOOD, \\ ALAN SUNDERLAND, RICHARD LANGTON HEWER, ELIZABETH WARD \\ From the Frenchay Stroke Unit, Department of Neurology, Frenchay Hospital, Bristol, UK
}

SUMMARY Four short, simple measures of arm function, suitable for use with patients recovering from acute stroke, are described. These tests are: the Frenchay Arm Test, the Nine Hole Peg Test, finger tapping rate and grip strength. Good interobserver and test-retest reliability was demonstrated for all tests, and the Frenchay Arm Test was shown to be valid. Normal values for all tests were established on 63 controls. It was found that the limited sensitivity of the Frenchay Arm Test could be improved using the Nine Hole Peg Test and grip strength. Recovery of arm function has been studied in a sample of 56 patients seen regularly over the first 3 months after their stroke, using these standard measures. The results demonstrated a wide variation in recovery curves between patients. The use of the Nine Hole Peg Test enabled further recovery to be detected after patients achieved a top score on the Frenchay Arm Test. Failure to recover measureable grip strength before 24 days was associated with absence of useful arm function at three months. Measurement of finger tapping rate was not useful.

Progress in science is dependent upon, and frequently follows, the development of new measurement techniques. In the context of controlled trials of physiotherapeutic techniques, the major requirements are that any measure should be: valid, reliable when used by different observers, simple enough to be used on patients who are often old and suffering other problems, and sensitive enough to detect clinically significant differences. This paper discusses measures of arm function which might fulfil these criteria.

Several tests of arm function have been published. One of the first, developed by Carroll, ${ }^{1}$ was long and has since been shortened and renamed the Action Research Armtest. ${ }^{2}$ Tests of motor function ${ }^{34}$ often include specific tests of arm function. It is probable that most tests give similar results. ${ }^{5}$

Our unit has had an interest in recovery of arm function after stroke, and its measurement, for some years. ${ }^{67}$ Starting with 25 clinical tests we have reduced the number to five which now constitute the

Address for reprint requests: Dr R Langton Hewer, Department of Neurology, Frenchay Hospital, Bristol BS16 1LE, UK.

Received 4 March 1986 and in revised form 8 August 1986. Accepted 23 September 1986.
Frenchay Arm Test. In the first part of this paper weô wish to establish the validity and reliability of the Frenchay Arm Test and compare it with some other tests of function which may add sensitivity. We then present data on recovery of arm function in the first 3 months after stroke, utilising the tests described, particularly investigating the variation among individuals.

The rate of recovery of use in an arm paralysed after an acute stroke is usually fastest in the early weeks, with little change occurring after one year. ${ }^{68}$ Good recovery is unlikely if no movement is seen by one month. ${ }^{8}$ Recovery in other functions seems to follow a similar pattern: for example, general function, ${ }^{910}$ proprioception, ${ }^{11}$ and complex cognitive functions. ${ }^{12}$ Most of these studies have presented information in terms of the average ability of all patients. One criticism of this approach is that individual variability is lost, possibly leading to unjustified pessimism concerning patients who apparently have a poor prognosis. A further difficulty arises in trying to distinguish between adaptive recovery (that is, learning new ways of achieving old ends) and intrinsic recovery. ${ }^{13}$ The recovery of arm function might reflect intrinsic recovery. ${ }^{6}$ 
The tests

Four separate tests will be discussed:

(a) The Frenchay Arm Test, which takes less than 3 minutes to complete, consists of five pass/fail tasks, the patient scoring 1 for each one completed successfully. The patient sits at a table with his hands in his lap, and each task starts from this position. He is then asked to use his affected arm/hand to:

1 Stabilise a ruler, while drawing a line with a pencil held in the other hand. To pass, the ruler must be held firmly.

2 Grasp a cylinder ( $12 \mathrm{~mm}$ diameter, $5 \mathrm{~cm}$ long), set on its side approximately $15 \mathrm{~cm}$ from the table edge, lift it about $30 \mathrm{~cm}$ and replace without dropping.

3 Pick up a glass, half full of water positioned about 15 to $30 \mathrm{~cm}$ from the edge of the table, drink some water and replace without spilling.

4 Remove and replace a sprung clothes peg from a $10 \mathrm{~mm}$ diameter dowel, $15 \mathrm{~cm}$ long set in a $10 \mathrm{~cm}$ base, 15 to $30 \mathrm{~cm}$ from table edge. Not to drop peg or knock dowel over.

5 Comb hair (or imitate); must comb across top, down the back and down each side of head.

(b) Grip Strength was measured using a dynanometer (a bulb connected to an aneroid dial) on both the affected and unaffected sides. The maximum grip recordable was $300 \mathrm{~mm}$ $\mathrm{Hg}$, which may affect our "normal" findings. The score was also recorded as a percentage of the unaffected side.

(c) The Nine Hole Peg Test. ${ }^{14}$ Sitting at a table, the patient is asked to take 9 dowels ( $9 \mathrm{~mm}$ diameter, $32 \mathrm{~mm}$ long) from the table top and put them into 9 holes $(10 \mathrm{~mm}$ diameter, 15 $\mathrm{mm}$ deep) spaced $50 \mathrm{~mm}$ apart on a board. The time to complete this is recorded, with a cut-off at $\mathbf{5 0}$ seconds (when the number placed is recorded). The number of pegs placed per second is then calculated.

(d) The fourth test was to measure the Finger Tapping Rate of the index finger over 10 seconds, using a mechanical counter. This was done twice with the unaffected hand, and then twice with the affected hand. The best score was taken for each side, and the percentage of the normal side recorded.

In practice it was found best to start with assessment of grip strength, then to do the Frenchay Arm Test, Nine Hole Peg Test and finally finger tapping rate, because the patient is more likely to succeed with the earlier tests.

\section{Normal controls}

Sixty three age-matched people, most from local "senior citizens" social clubs, were tested. Their average (SD) age was $72.0(9.9)$ years (median 73, range 47-92).

For the Frenchay Arm Test all subjects were asked to perform each task using the dominant and non-dominant hands. All scored 5/5. For the Nine Hole Peg Test alternate subjects were asked to use the dominant and non-dominant hands. There was little difference between performance using dominant $(n=30$, mean peg/s 0.68 , median 0.67 , SD 0.14 , range $0.35-1 \cdot 0)$, or non-dominant $(n=33$, mean 0.65 , median $0 \cdot 64$, SD $0 \cdot 12$, range $0 \cdot 41-0 \cdot 9)$ hands $(t=0 \cdot 73, \mathrm{NS})$.

For grip strength and finger tapping, alternate subjects were asked to commence with the dominant and nondominant hands. For dominant hand grip strength, 36 of 59 subjects scored $300 \mathrm{~mm}$, the remainder scoring between 85 and $300 \mathrm{~mm}$; only three $(5 \%)$ scored below $225 \mathrm{~mm}$. (Four subjects had such severe arthritis that they could not be tested.) The non-dominant scores were over $300 \mathrm{~mm}$ in 34 of
59 subjects. Of the remainder, 10 scored below $225 \mathrm{~mm}$ and the fifth percentile was $160 \mathrm{~mm} \mathrm{Hg}$. When a subject's score was expressed as a percentage of the other side, the scores ranged between $80-140 \%$ on the dominant side and $75-125 \%$ on the non-dominant side. Interpretation is complicated by the artificial ceiling of $300 \mathrm{~mm}$ on the score achievable.

The finger tapping rate was variable, being between 22 and 51 per 10 seconds on the dominant side, and 18-46 on the non-dominant side. When expressed as a percentage of the other side, the range was $90 \%-148 \%$ on the dominant side and $68 \%-112 \%$ on the non-dominant side.

Correlation coefficients between age and pegs per second recorded on the Nine Hole Peg Test demonstrated that age had some effect $(r=-0.42, p<0.01)$, but only accounted for $17 \%$ of the variance. The correlation coefficients between age and grip strength on the dominant and non-dominant side and finger tapping rate on both sides were not significant ( $\mathrm{r}=-0.02$ to 0.05 ).

From these results, we have used the following criteria for normal:

1 Complete success on the Frenchay Arm Test (that is, $5 / 5)$.

2 Completion of the Nine Hole Peg Test in $18 \mathrm{~s}$ or less $(0.5$ $\mathrm{peg} / \mathrm{s})$. Three $(5 \%)$ normal controls were outside this cut-off (one scored 0.45 , one 0.41 and one 0.35 pegs/s).

3 For grip strength: $75 \%$ of the other side without regard of the dominance of the tested hand. This cut-off, which is the lower limit of our normal subjects, may need revision if using a dynanometer able to record over $300 \mathrm{~mm} \mathrm{Hg}$.

4 For finger tapping: $68 \%$ of the other side without regard of the dominance of tested hand. This was the lower limit of our normal subjects.

\section{Reliability}

Test-retest reliability for all four tests was assessed by two observers (a research psychologist and VW) on 10 stroke patients who attended a weekly group in the Speech Therapy department. They were selected on the basis of having reduced arm function and having suffered their stroke more than 18 months previously. All 10 patients were tested on three occasions at weekly intervals. The first and third assessments were performed by one observer (VW), the second assessment was by the other observer. The testers recorded the patient's responses on new assessment sheets on each occasion without referring to previous results. The time taken to complete the Frenchay Arm Test was recorded and ranged from 1 to 3 minutes.

Test-retest Spearman rho correlations were calculated for the Frenchay Arm Test total score, grip strength on the normal and weak sides, finger tapping rate on the normal and weak sides, and the Nine Hole Peg Test. The results were $0.83-0.99$ between observer $1 /$ test 1 and observer $2 /$ test 2 ; $0.68-0.90$ between observer $1 /$ test 1 and observer $1 /$ test 3 ; and $0.75-0.99$ between observer $2 /$ test 2 and observer $1 /$ test 3. All these are statistically significant, strong associations ( $p$ $>0.025-p<0.001$ ) indicating good inter-observer and testretest reliability for each test.

\section{Validity of the Frenchay Arm Test}

Fourteen survivors who had previously been studied ${ }^{6} 5$ to 7 years ago were reassessed (by EW). These patients had all suffered some loss of arm use when first seen within 8 weeks 
of their stroke, had all achieved 5/5 on the Frenchay Arm Test 2 or 3 years later, and achieved $5 / 5$ when retested now. In other words, they had all apparently made and maintained a full recovery. This sample comprised five men and nine women; seven had originally had a left hemiplegia and seven a right hemiplegia; their average age at reassessment was $68 \cdot 3$ years (range 55-87).

To test whether they actually used their affected arms, they were asked to perform five tasks that are normally achieved bilaterally (as shown in a control sample; $\mathbf{n}=10$ ). The subject was observed, without being told the purpose of the activities, and scored on a specific point of each task:

1 Put on a loosely fitting jacket and fasten four buttons. Scored on use of one or two hands to fasten buttons.

2 Given knife and fork and asked to eat a piece of flan. Scored on use of one or two pieces of cutlery.

3 Given a pen with its top on and asked to write. Scored on use of one or two hands to remove top from pen.

4 Asked to take coin from purse with stud fastener. Scored on use of one or two hands to open purse.

5 Asked to catch a ball thrown from approximately four feet away. Scored on use of one or two hands to catch ball.

Twelve patients used both hands for all five tasks. One patient used only his dominant, unaffected arm to eat the flan (American style), and one only used two hands for tasks 3 and 5 . However, only four of the 14 patients felt that their arm had fully recovered. Five felt that there were a few things they could not use their arm for, and five felt that they still had a major handicap. We conclude that the Frenchay Arm Test is a valid test of arm function-patients scoring $5 / 5$ are likely to use their arm even if they feel it is not normal.

\section{Recovery of arm function}

Patients and Method The study of recovery is based upon a 3 month follow-up of 117 consecutive admissions to Frenchay Hospital of patients suffering an acute stroke. Every patient was seen as soon as possible following admission, a neurological history and examination recorded and the diagnosis confirmed using the WHO definition. ${ }^{15}$ Arm function was assessed using the four tests described. Each patient was, where possible, assessed weekly in hospital and every two weeks following discharge until 13 weeks post stroke.

\section{Results}

Of the 117 patients initially registered, 40 died before three months, 12 were lost to follow-up, three were found to have cerebral tumours, three subsequently developed illnesses which led to late deterioration (all three were recovering before their second illness), one had a congenital hemiplegia of the side affected by his stroke, one had severe comprehension loss and his results were not considered reliable and one was uncooperative. These were excluded, leaving 56 patients which form the basis of the study.

The characteristics of the 56 patients were as follows: 24 were men and 32 women; their average age was 68.1 years (SD 11.4); 28 had right-sided weak-

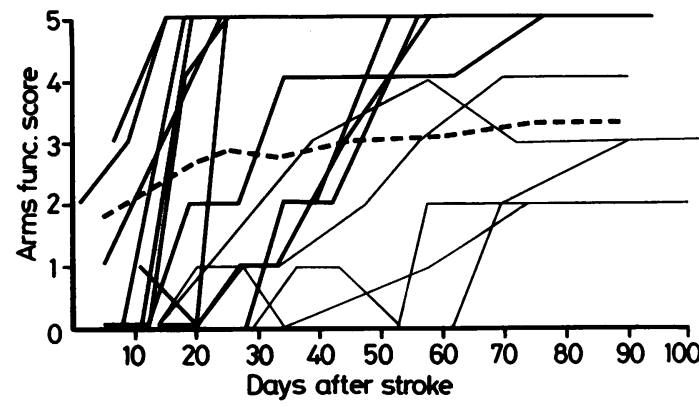

Fig 1 Recovery of arm function; Frenchay Arm Test scores. Heavy lines-11 patients achieving top score (5/5). Light lines-5 patients achieving score between 1-4. Interrupted line-mean score for all 56 patients.

ness, 25 left-sided weakness amd three had no unilateral weakness; on initial assessment 21 were fully conscious, 30 mildly confused or drowsy and five unconscious; 25 had visual inattention or hemianopia; 13 had sensory inattention; and the average (SD) delay to first clinical assessment was $4 \cdot 6(6 \cdot 1)$ days.

\section{(1) The Frenchay Arm Test}

Seventeen $(30 \%)$ patients scored "0" and $19(34 \%)$ scored " 5 " (maximum) throughout. One patient with a frozen shoulder scored $4 / 5$ throughout, two scored $4 / 5$ initially for reasons unrelated to lost arm function (one Polish patient could not understand the instructions, one patient had a fractured wrist) but scored $5 / 5$ thereafter, and one initially unconscious patient scored $5 / 5$ on the Frenchay Arm Test when first assessed after regaining consciousness.

The recovery curves of the remaining 16 patients are plotted in fig 1 . The mean score for the whole

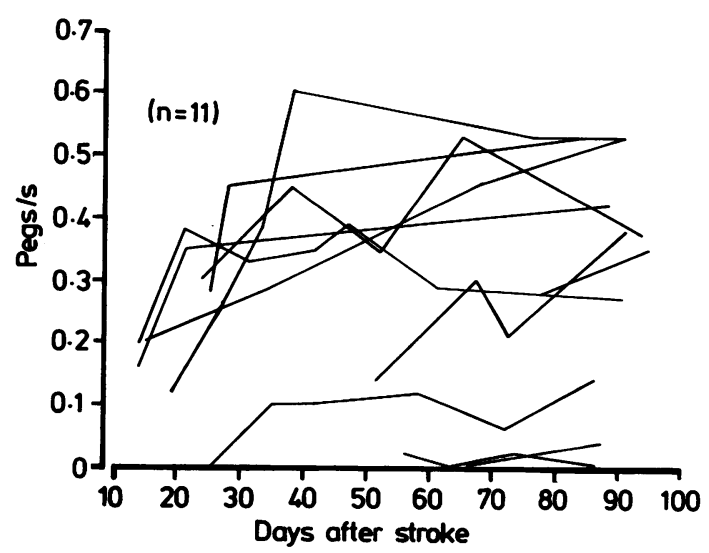

Fig 2 Recovery of arm function. 11 patients after scoring 5/5 on Frenchay Arm Test. 


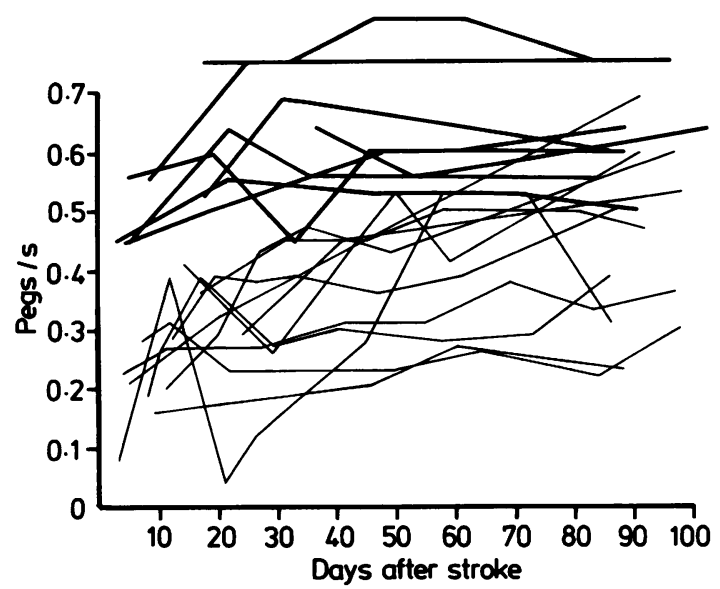

Fig 3 Recovery of arm function: speed on Nine Hole Peg Test. Heavy lines - 8 patients making a rapid recovery. Light lines-11 patients making a slower recovery.

group (that is, all 56) is also shown, using interpolated scores when assessments were missing, the values used being calculated by assuming a steady change between the two nearest known values. The figure shows that the mean score of the group hides wide variation between individuals. However, 11 of the 16 patients achieved $5 / 5$ on the Frenchay Arm Test within 13 weeks and all of these had started recovering by 5 weeks.

\section{(2) The Nine Hole Peg Test}

To test if further recovery could be detected after a patient scored $5 / 5$ on the Frenchay Arm Test, the sequential scores on the Nine Hole Peg Test (peg/s) of the 11 patients who made a full recovery were plotted, starting from the point of achieving $5 / 5$ on the Frenchay Arm Test (fig 2). This demonstrates that some further recovery could be detected in nine of the 11 patients, but only three patients actually achieved a normal performance by 3 months. Figure 3 shows the recovery of speed on the Nine Hole Peg Test for the 19 patients who scored $5 / 5$ on the Frenchay Arm Test throughout. Five were within normal limits at first assessment and three more became normal within three weeks. The remaining 11 patients all showed some improvement but again only three eventually achieved a normal performance. Considering all 33 patients who scored 5/5 on the Frenchay Arm Test at 3 months post-stroke, only $17(52 \%)$ were within normal limits on the Nine Hole Peg Test. These results suggest that the Nine Hole Peg Test is a more sensitive test of arm function than the Frenchay Arm Test.

\section{(3) Grip Strength and finger tapping rate}

Twenty three ( $41 \%$ ) of the 56 patients were unable to score on the dynanometer at their initial attempt (that is, could not achieve $30 \mathrm{~mm} \mathrm{Hg}$ ) and in 10 this continued throughout the study. Of the 13 who did subsequently achieve measureable grip (over $30 \mathrm{~mm}$ ), all did so by 24 days, but only six went on to show any recovery on the Frenchay Arm Test, three achieving $5 / 5$. Recovery of recordable grip strength nearly always preceded other measurements of arm function during recovery and suggests that this is the most sensitive test of initial recovery.

The results of the finger tapping rate showed that it was never the first test to recover. Further, as shown later, only one patient was abnormal on this test alone and normal on the other tests. Therefore it seems to add little information when studying recovery.

\section{Sensitivity}

The results so far suggest that the Frenchay Arm Test is a valid measure of arm function after stroke. However, subjective difficulties often still remain in patients with a normal score, indicating its limited sensitivity; previous research ${ }^{6}$ has also shown the limited sensitivity of the Frenchay Arm Test at both the upper and lower ends.

The results from assessment at 3 months (table) showed that all patients scoring less than $5 / 5$ on the Frenchay Arm Test were correctly identified as abnormal when using "normal" cut-offs on Nine Hole Peg Test, all but one (who scored $4 / 5$ on the Frenchay Arm Test) were correctly identified as abnormal on grip strength, and all but two were correctly identified abnormal on finger tapping rate. More interesting is the finding that $16(48 \%)$ patients who scored $5 / 5$ on the Frenchay Arm Test were outside normal limits on the Nine Hole Peg Test, six $(18 \%)$ on finger tapping rate and five $(15 \%)$ on grip

Table Relative sensitivity of tests $(n=56)$

\begin{tabular}{|c|c|c|c|c|c|c|c|c|c|c|}
\hline \multirow{2}{*}{\multicolumn{2}{|c|}{$\begin{array}{l}\text { Frenchay } \\
\text { Arm Test score }\end{array}$}} & \multicolumn{3}{|c|}{ Nine Hole Peg Test } & \multicolumn{3}{|c|}{ Grip strength } & \multicolumn{3}{|c|}{ Finger tapping rate } \\
\hline & & Normal* & Abnormal & “0” & Normal & Abnormal & “0” & Normal & Abnormal & “0” \\
\hline $\begin{array}{l}5 / 5 \\
1-4 / 5 \\
0 / 5\end{array}$ & $\begin{array}{l}(\mathrm{n}=33) \\
(\mathrm{n}=6) \\
(\mathrm{n}=17)\end{array}$ & $\begin{array}{r}17 \\
0 \\
0\end{array}$ & $\begin{array}{r}16 \\
5 \\
0\end{array}$ & $\begin{array}{r}0 \\
1 \\
17\end{array}$ & $\begin{array}{r}28 \\
1 \\
0\end{array}$ & $\begin{array}{l}5 \\
5 \\
7\end{array}$ & $\begin{array}{r}0 \\
0 \\
10\end{array}$ & $\begin{array}{r}27 \\
2 \\
0\end{array}$ & $\begin{array}{l}6 \\
4 \\
1\end{array}$ & $\begin{array}{r}0 \\
0 \\
16\end{array}$ \\
\hline
\end{tabular}

*Normal, above cut-off; Abnormal, below cut-off, but more than "0"; “0”, unable to score. 
strength. This would suggest that the Nine Hole Peg Test and the other tests are able to detect impaired function in the presence of a "normal" Frenchay Arm Test result. The table also shows that a recordable grip strength was found in seven out of 17 patients who scored " 0 " on the Frenchay Arm Test, confirming that it might also be able to detect the early stages of recovery.

\section{Discussion}

The results suggest that the Frenchay Arm Test, the Nine Hole Peg Test, finger tapping rate and measurement of grip strength are valid and reliable measures of arm function in neurologically disabled patients, particularly after stroke. We have not compared the Frenchay Arm Test with the Action Research Armtest, the other well researched test of arm function. However, we note that the Action Research Armtest takes an average of 8 minutes to complete $^{5}$ and requires considerably more equipment than the Frenchay Arm Test, both factors which militate against its use in routine clinical practice. The Fugl-Meyer arm assessment takes longer still, ${ }^{5}$ though it only requires a tendon hammer.

The limited sensitivity of the Frenchay Arm Test at both ends of the range has always been its major drawback. Our results suggest that the use of the Nine Hole Peg Test can increase the sensitivity of measurement of arm function at the upper range of ability, even in the population of stroke patients who are likely to have pre-existing problems with their hands. The sensitivity at the lower range appears to be increased using grip strength, in that seven out of 16 patients who scored " 0 " on the Frenchay Arm Test nevertheless had recordable grip strength. An alternative way of detecting early recovery might be to use some of the arm movements from the Motor Club Stroke Assessment. ${ }^{3}$ Although the finger tapping rate is potentially a sensitive test, the wide variability seen between patients limits it utility. It might have a limited role in following individual recovery.

The results also confirm earlier findings that recovery of arm function is concentrated in the first 3 months, ${ }^{68}$ but emphasise the wide variation between the patients' mean and individual scores. Recordable grip strength was the first function to recover, followed by improvement on the Frenchay Arm Test; those patients destined to make a significant recovery can expect to achieve the former by three weeks, the latter by five. Conversely, failure to do so signified a poor prognosis. A more sophisticated dynanometer with an extended upper limit might prove the most versatile single test, with the ability to include those patients with marked disability unable to register on other tests, yet also able to detect late recovery. The
Nine Hole Peg Test clearly demonstrated further recovery in those with maximal scores on the Frenchay Arm Test, with this improvement continuing up to 3 months.

Patients for the study of recovery were selected by virtue of being admitted to hospital and then surviving 3 months. They included a wide range of severities; five patients were unconscious initially, whereas 21 had no impairment in conscious level, and 25 had visual field defects, suggesting the sample should be representative of patients recovering from stroke. Those patients lost to follow up or otherwise excluded were not obviously different.

Since there is so much individual variation, is it possible to predict with any certainty the degree of recovery in a particular patient and, if so, how early can this prediction be made? Bard and Hirschberg ${ }^{8}$ found that those making a full recovery showed some improvement within the first month, a result confirmed by our study. Any patient without observable movement or recordable finger grip by 28 days is unlikely to recover any useful function and this information might be used to make a relatively early decision with regard to further therapy, either towards more intensive treatment or towards acceptance of the lack of function, with adaptive training to using the unaffected arm.

Recovery in arm function seems similar to that seen in other areas. In a parallel study on walking in the same patients ${ }^{16}$ the importance of early recovery as a prognostic marker was again seen. Those patients making a good recovery were all walking again by one month.

We conclude that these tests form a useful battery for measuring arm function. Grip strength appears to be the most sensitive at the lower range of function and Nine Hole Peg Test the most sensitive at the upper range. The use of grip strength as a measure needs further investigation using more modern instruments without an upper limit. Furthermore, despite the wide individual variation seen in recovery after stroke, realistic predictions of recovery of useful function, or lack of it, can be made relatively early.

We are grateful to all the physicians who allowed us to study their patients, to all ward and stroke unit staff who cooperated fully with this study, and to the patients. We thank the Chest Heart and Stroke Association for their continuing support. Mrs J LeghSmith helped in assessing reliability.

\section{References}

1 Carroll D. Hand function in hemiplegia. J Chron Dis 1965;18:493-500.

2 Lyle RC. A performance test for assessment of upper 
limb function in physical rehabilitation treatment and research. Int J Rehab Res 1981;4:483-92.

3 Ashburn A. A physical assessment for stroke patients. Physiotherapy 1982;68:109-13.

4 Fugl-Meyer AR, Jaasko L, Leyman I, Olsson S, Steglind S. The post-stroke hemiplegic patient. 1: A method for evaluation of physical performance. Scand J Rehab Med 1975;7:13-31.

5 De Weerdt WJG, Harrison MA. Measuring recovery of arm-hand function in stroke patients: A comparison of the Brunnstrom-Fugl-Meyer test and the Action Research Arm test. Physiotherapy Canada 1985;37: 65-70.

6 Wade DT, Langton Hewer R, Wood VA, Skilbeck CE, Ismail HM. The hemiplegic arm after stroke: measurement and recovery. J Neurol Neurosurg Psychiatry 1983;46:521-4.

7 De Souza LH, Langton Hewer R, Miller S. Assessment of recovery of arm control in hemiplegic stroke patients. I: Arm function tests. Int Rehab Med 1980;2:3-9.

8 Bard G, Hirschberg GG. Recovery of motion in upper extremity following hemiplegia. Arch Phys Med Rehabil 1965;46:567-72.

9 Skilbeck CE, Wade DT, Langton Hewer R, Wood VA. Recovery after stroke. J Neurol Neurosurg Psychiatry 1983;46:5-8.
10 Wade DT, Wood VA, Langton Hewer R. Recovery after stroke: the first 3 months. $J$ Neurol Neurosurg Psychiatry 1985;48:7-13.

11 Smith DL, Akhtar AJ, Garraway WM. Proprioception and spatial neglect after stroke. Age Ageing 1983; 12:63-9.

12 Hier DB, Mondlock J, Caplan LR. Recovery of behavioural abnormalities after right hemisphere stroke. Neurology 1983;33:345-50.

13 Wade DT, Langton Hewer R, Skilbeck CE, David RM. Stroke: A Critical Approach to Diagnosis, Treatment and Management. London: Chapman and Hall, 1985: $180-4$.

14 Sharpless JW. The nine-hold peg test of finger hand coordination for the hemiplegic patient. In: Mossman's A Problem Oriented Approach to Stroke Rehabilitation. Springfield, Illinois: Charles C Thomas, 1982:470-3.

15 Aho K, Harmsen P, Hatano S, Marquardsen J, Smirnov VE, Strasser T. Cerebrovascular disease in the community: results of a WHO collaborative study. Bull WHO 1980;58:113-30.

16 Wade DT, Wood VA, Heller A, Maggs J, Langton Hewer R. Walking after stroke: measurement and recovery over the first 3 months. Scand J Rehab Med (in press). 